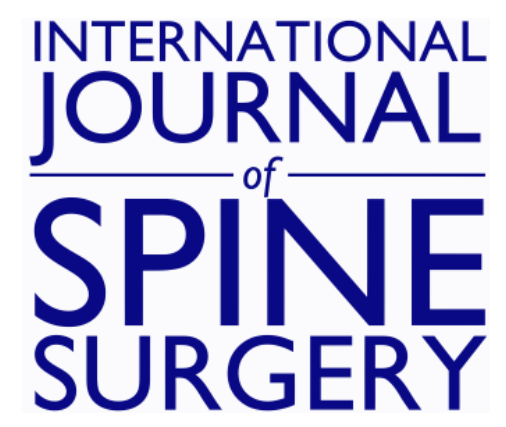

\title{
Two-Year Outcomes from a Randomized Controlled Trial of Minimally Invasive Sacroiliac Joint Fusion vs. Non-Surgical Management for Sacroiliac Joint Dysfunction
}

David W. Polly, John Swofford, Peter G. Whang, Clay J. Frank, John A. Glaser, Robert P. Limoni, Daniel J. Cher, Kathryn D. Wine, Jonathan N. Sembrano and and the INSITE Study Group

Int J Spine Surg 2016, 10 ()

doi: https://doi.org/10.14444/3028

http://ijssurgery.com/content/10/28

This information is current as of April 26, 2023.

Email Alerts Receive free email-alerts when new articles cite this article. Sign up at:

http://ijssurgery.com/alerts The International Journal of Sping Surgerhy
2397 Watterbury Circle, Suite 1,

Aurora, IL 60504, Phone: +1-630-375-1432

(C) 2016 ISASS. All Rights Reserved. 


\section{Two-Year Outcomes from a Randomized Controlled Trial of Minimally Invasive Sacroiliac Joint Fusion vs. Non-Surgical Management for Sacroiliac Joint Dysfunction}

David W. Polly, MD, 1 John Swofford, MD, 2 Peter G. Whang, MD, ${ }^{3}$ Clay J. Frank, MD, 4 John A. Glaser, MD, 5 Robert P. Limoni, MD, 6 Daniel J. Cher, $M D, 7$ Kathryn D. Wine, MPH, Jonathan N. Sembrano, $M D, 8$ and the INSITE Study Group.

${ }_{1}$ Departments of Orthopedic Surgery and Neurosurgery, University of Minnesota, Minneapolis, MN 2Indiana Interventional Pain, Indiana Surgery Center East, Indianapolis, IN ${ }^{3}$ Department of Orthopaedics and Rehabilitation, Yale University School of Medicine, New Haven CT 4 Integrated Spine

Care, Wauwatosa, WI ${ }^{5}$ Medical University of South Carolina, Charleston, SC ${ }^{6}$ Aurora BayCare Orthopedic \& Sports Medicine Center, Green Bay, WI ${ }^{7}$ SI$B O N E$, Inc., San Jose, $C A{ }^{8}$ Department of Orthopaedic Surgery, University of Minnesota, Minneapolis, $M N$

\section{Abstract}

\section{Background}

Sacroiliac joint (SIJ) dysfunction is an important and underappreciated cause of chronic low back pain.

Objective

To prospectively and concurrently compare outcomes after surgical and non-surgical treatment for chronic SIJ dysfunction.

\section{Methods}

One hundred and forty-eight subjects with SIJ dysfunction were randomly assigned to minimally invasive SIJ fusion with triangular titanium implants $(\mathrm{SIJF}, \mathrm{n}=102)$ or non-surgical management $(\mathrm{NSM}, \mathrm{n}=46)$. SIJ pain (measured with a 100-point visual analog scale, VAS), disability (measured with Oswestry Disability Index, ODI) and quality of life scores were collected at baseline and at scheduled visits to 24 months. Crossover from non-surgical to surgical care was allowed after the 6-month study visit was complete. Improvements in continuous measures were compared using repeated measures analysis of variance. The proportions of subjects with clinical improvement (SIJ pain improvement $\geq 20$ points, ODI $\geq 15$ points) and substantial clinical benefit (SIJ pain improvement $\geq 25$ points or SIJ pain rating $\leq 35$, ODI $\geq 18.8$ points) were compared.

Results

In the SIJF group, mean SIJ pain improved rapidly and was sustained (mean improvement of 55.4 points) at month 24. The 6-month mean change in the NSM group (12.2 points) was substantially smaller than that in the SIJF group (by 38.3 points, $\mathrm{p}<.0001$ for superiority). By month $24,83.1 \%$ and $82.0 \%$ received either clinical improvement or substantial clinical benefit in VAS SIJ pain score. Similarly, $68.2 \%$ and $65.9 \%$ had received clinical improvement or substantial clinical benefit in ODI score at month 24. In the NSM group, these proportions were $<10 \%$ with non-surgical treatment only. Parallel changes were seen for EQ-5D and SF-36, with larger changes in the surgery group at 6 months compared to NSM. The rate of adverse events related to SIJF was low and only 3 subjects assigned to SIJF underwent revision surgery within the 24-month follow-up period.

\section{Conclusions}

In this Level 1 multicenter prospective randomized controlled trial, minimally invasive SIJF with triangular titanium implants provided larger improvements in pain, disability and quality of life compared to NSM. Improvements after SIJF persisted to 24 months.

This study was approved by a local or central IRB before any subjects were enrolled. All patients provided studyspecific informed consent prior to participation.

KEYWORDS: SACROILIAC JOINT DYSFUNCTION, SACROILIAC JOINT FUSION, MINIMALLY INVASIVE SURGERY, RANDOMIZED CLINICAL TRIAL 


\section{Background}

The sacroiliac joint (SIJ) is an anatomic structure that is increasingly being recognized as a potential cause of chronic low back and buttock pain. The SIJ contains both mechanoreceptors ${ }^{1}$ and nociceptive receptors. ${ }^{2}$ SIJ degeneration commonly occurs, ${ }^{3}$ especially after lumbar fusion. ${ }^{4}$ Provocative physical examination tests that stress the SIJ are predictive of a positive response to intraarticular SIJ block. ${ }^{5}$ Pressurization of the SIJ in healthy volunteers can elicit pain $^{6}$ and local anesthetics delivered onto exiting dorsal sacral nerve roots block sensation outside of the joint but not pain elicited by joint pressurization, a finding suggestive of the existence of specific neural pathways. ${ }^{7}$ SIJ pain can be very debilitating, with patients reporting ODI scores in the 50s. ${ }^{8-13}$ The burden of disease associated with SIJ pain is at least as high as that associated with other musculoskeletal conditions such as hip osteoarthritis, degenerative spondylolisthesis or spinal stenosis, conditions that are often treated surgically. ${ }^{14,15}$

The SIJ has been shown to be a frequent source of low back pain and is thought to be involved in 15-30\% of all patients with chronic low back pain. ${ }^{16-19}$ The prevalence of block-proven SIJ dysfunction is even higher in patients with low back pain after lumbar fusion. ${ }^{20-22}$ Common causes of SIJ-mediated pain include osteoarthritic degeneration, disruption of the SIJ related to trauma or pregnancy, inflammatory arthritis, tumor, and infection. It is likely that in some cases, lumbar spinal fusion may be performed inappropriately when the true underlying source of pain is the SIJ. This evidence, combined with blinded trials of intervention treatments, ${ }^{23-26}$ validate the SIJ as a diagnosis and make it clear that the SIJ, hip and spine should all be included in the differential diagnosis early in the workup of patients with chronic low back pain.

A specific diagnosis of SIJ-mediated pain can be reliably achieved with a composite battery of physical examination maneuvers that stress the SIJ. If at least 3 of these physical examination maneuvers are positive, the pre-test probability of a positive imageguided intra-articular local anesthetic injection increases to $85 \% .^{5}$
Non-surgical treatments for SIJ disorders include medication management, SI belts, physical therapy (PT), SIJ chiropractic manipulation, intraarticular steroid injections, prolotherapy, and radiofrequency (RF) ablation. Two blinded trials each suggest shortterm effectiveness for periarticular steroids ${ }^{23,24}$ and $\mathrm{RF}$ ablation of sacral nerve roots. ${ }^{25,26}$ Return of pain 6 to 12 months following RF ablation is common secondary to regeneration of nerve innervation. No high-quality data exist for intraarticular steroid injections (a treatment more commonly provided in the US than periarticular steroids).

For patients with disabling symptoms attributable to the SIJ who do not respond to non-surgical treatments, surgical management is a reasonable option. Open surgery has a long but incompletely documented track record, with the first SIJ fusion (SIJF) reported in $1908 .{ }^{27}$ Because the "collateral damage" to the surrounding anatomic structures associated with open SIJF is significant, this procedure is no longer routinely performed for chronic SIJ dysfunction. More recently, minimally invasive techniques with novel implants have been developed that are designed to confer the benefits of permanent SIJ stabilization but have a more reasonable safety profile. To date, most published data describe use of a lateral transfixing approach. While a small number of studies describe use of hollow modular anchor screws, ${ }^{9,28}$ a larger number describe use of triangular titanium implants with a porous surface. ${ }^{8,10-13,29-34}$ We report herein the 2-year results of the first randomized controlled trial comparing minimally invasive SIJF with triangular titanium implants to non-surgical management.

\section{Methods}

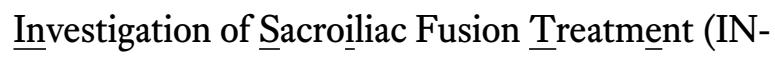
SITE, NCT01681004) is a prospective, multicenter, parallel-group, open-label randomized controlled trial. Enrollment occurred between January 2013 and May 2014 at 19 institutions in the United States after local or regional institutional review board study approval. Physician participants were diverse, and included academic institutions and private practices across the US. The study was sponsored by the device's manufacturer (SI-BONE, Inc., San Jose, CA, 
USA), which included payment for the index and crossover surgical procedures and NSM treatments within the study. All study sites underwent both remote and regular on-site data monitoring (including source verification).

Eligibility. Adult patients (age 21-70 years) were eligible to participate if they had a confirmed diagnosis of unilateral or bilateral SIJ dysfunction due to degenerative sacroiliitis and/or sacroiliac joint disruption established from typical historical findings (pain in the back below L5, buttocks or legs, including a positive Fortin finger test ${ }^{35}$ ), SIJ pain elicited on at least 3 of 5 established physical examination provocative tests, ${ }^{5}$ and confirmation with at least a $50 \%$ decrease in SIJ pain 30 or 60 minutes after imageguided sacroiliac joint block with local anesthetic. All blocks were arthrogram-confirmed and performed within 3 months prior to screening. Planned bilateral patients had confirmatory blocks on both SIJs prior to study entry. Patients had degenerative sacroiliitis on the basis of radiographic findings of sclerosis, osteophytes, cysts or vacuum phenomenon in or around the joint, or disruption on the basis of asymmetric widening of the joint or leakage of contrast on diagnostic arthrography. Other inclusion criteria were a baseline Oswestry Disability Index ${ }^{36}$ (ODI) score of at least 30 and an SIJ pain score ("average SIJ pain in the last week"), rated using a visual analog scale, of least at least 50 on a $0-100$ visual ana$\log$ scale (VAS).

Patients were excluded if any of the following criteria were present: inability to confirm that the pain is arising from the SIJ, SIJ pain secondary to inflammatory conditions, severe back pain deemed to be due primarily to other causes (e.g., lumbar disc degeneration, spinal stenosis, etc.), history of recent (within 1 year) major trauma to the pelvis, metabolic bone disease (either induced or idiopathic), or any other condition that made treatment with the study devices infeasible or interfered with the ability of the subject to participate in physical therapy. Patients involved in litigation, on disability leave, or receiving workers' compensation related to their back or SIJ pain were also excluded. Patients who agreed to enroll signed a study-specific IRB-approved informed consent form.
Baseline assessments. At baseline, a detailed medical history and physical examination was performed by investigators, and study team members (typically study coordinators) administered the following questionnaires to subjects: SIJ and lower back pain using the above-described VAS, ODI, EuroQoL-5D ${ }^{37}$ (EQ-5D), and Short Form-36 ${ }^{38}$ (SF-36), all of which are commonly used in spine surgery studies and are further described elsewhere.

Randomization and blinding. After baseline assessment, subjects were randomly assigned to either SIJF or non-surgical management (NSM). Randomization was stratified by site and underlying diagnosis (degenerative sacroiliitis or SIJ disruption) in a 2:1 ratio to either SIJF or NSM with randomly chosen block sizes of 6 or 9 . Randomization sequences were computer-generated and obtained via a passwordprotected study website. Subjects were not blinded to treatment.

Interventions. NSM treatments were consistent with existing US practices and directed by each site investigator for each subject. They included pain medications as directed by the site investigator, physical therapy following American Physical Therapy Association (APTA) guidelines ${ }^{39}$ intraarticular SIJ steroid injections and radiofrequency $(\mathrm{RF})$ ablation of lateral branches of the sacral nerve roots, which were delivered in a stepwise fashion to address pain and disability according to each subject's individual needs. Cognitive behavioral therapy (CBT) was not included since no published data have supported the effectiveness of this treatment for SIJ pain and this treatment is not a prevalent modality in the modern US healthcare system. NSM treatments began within 30 days of randomization.

Minimally invasive SIJF was completed as described previously ${ }^{33}$ within 30 days of randomization unless there was a medically valid reason to delay surgery. All procedures were performed under general anesthesia using either 2-D fluoroscopy or 3-D computer navigation (2 study sites) based on intraoperative CT (O-arm) imaging according to the manufacturer's instructions for use. In summary, the procedure is performed through a lateral approach. After the gluteus muscle is bluntly dissected, a pin is inserted across 
the SIJ so that a cannulated drill and broach may be used to create a triangular-shaped cavity in the ilium and sacrum through which the titanium implant (see Device description below) is inserted. Postoperatively, subjects were discharged home at the surgeon's discretion, prior to which subjects were re-evaluated for the occurrence of adverse events. Subjects adhered to heel-toe touch-down weight-bearing using a frontwheeled walker or crutches for 3 weeks, which was progressively increased until they were fully ambulatory. In addition, subjects were asked to undergo individualized physical therapy (recommended twice a week for 6 weeks starting 1-3 weeks after surgery) as appropriate for their individual needs.

Device description. iFuse Implant System is a FDA-cleared triangular titanium implant with a porous titanium surface. The triangular shape allows for an interference fit with the surrounding bone that provides immediate stabilization and minimizes micromotion and rotation of the instrumented SIJ. The porous surface allows biological fixation to bone, a concept which is commonly utilized by several orthopaedic devices such as hip, knee, and shoulder prostheses. The iFuse implant is available in configurations from $30-70 \mathrm{~mm}$ in length and inscribed diameter of 4 or $7 \mathrm{~mm}$. In the vast majority of cases, $3 \mathrm{im}$ plants are placed across the joint.

Crossover. According to the protocol, subjects assigned to NSM were allowed to cross over to surgical treatment at any time after the 6-month visit was completed. During the trial design phase period, study investigators requested this crossover option for the following reasons: 1) patients with SIJ dysfunction have markedly reduced quality of life ${ }^{14} 2$ ) limited evidence is available to support the effectiveness of NSM for this condition, and 3) the preliminary results from SIJF using the study device were very promising. Investigators believed that precluding crossover would have unnecessarily hindered enrollment and likely have resulted in a non-

generalizable study population. Moreover, because the study device was already commercially available with reasonable insurance coverage, patients in many (but not all) centers could have simply elected to proceed with SIJF outside of the study rather than participating in the trial. This strategy was successful in that no subject initially assigned to NSM crossed over prior to the 6-month visit, the study's primary endpoint timing, enabling valid comparisons across interventions up to this time point.

Follow-up. All subjects were evaluated at follow-up visits scheduled at 1, 3, 6, 12, 18 and 24 months after assignment to NSM or the SIJF surgery had been performed. At each of these visits, subjects were assessed for overall health, ambulatory and work status, use of pain medications for SIJ or back pain, and physical examination findings (if relevant). Subjects also completed quality of life questionnaires and rated satisfaction with treatment. Adverse events, defined as any decrement in health (ISO 14155:2011), were also recorded over the 24 months of follow-up. In each adverse event report, investigators rated the severity and relationship of each event to the study device/procedure or non-surgical management treatment or any pre-existing conditions. Relatedness was captured as definitely, probably, possibly, unlikely or unrelated to the device, the SIJ treatment procedure (including non-surgical SIJ treatments) or preexisting condition. All adverse events were grouped by body system. Subjects assigned to SIJF underwent a pelvic X-ray at months 3 and 6 and a highresolution CT scan of the pelvis at month 24 . Radiographic findings will be described elsewhere.

\section{Statistical Methods}

The primary analysis cohort $(\mathrm{n}=148)$ consisted of subjects who were enrolled (i.e. were eligible and consented) and subsequently underwent the assigned study treatment. The primary study endpoint, evaluated at 6 months after the most recent SIJF (to accommodate subjects with planned staged bilateral surgery), was a binary success/failure composite measure. A subject was considered to be a success if all of the following criteria were met: reduction in VAS SIJ pain score by at least 20 points from baseline, absence of device-related serious adverse events, absence of neurological worsening related to the lumbosacral nerve roots, and absence of surgical re-intervention (i.e. removal, revision, reoperation, or supplemental fixation) for SIJ pain. The threshold of a 20-point decrease in VAS pain rating was selected because this has been shown to be the minimum 
clinically important difference for chronic lower back pain. ${ }^{40,41}$ An intent-to-treat approach was used for the 6-month primary endpoint such that any missing values were assumed to be failures. Further analysis of success rates was performed using available data only and focused on success relevant to the assigned treatment. For example, a subject who crossed over from NSM to surgical treatment could not be counted as an NSM success since surgery is not a component of NSM.

We further assessed pain and function scores and quality of life endpoints by reporting mean scores according to treatment and visit. We defined improvement as the proportions of subjects with improvement as those with SIJ pain score improvements of at least 20 points and ODI of 15 points, ${ }^{42}$ and substantial clinical benefit as the proportion with a 25-point improvement in pain rating or a pain rating score $\leq 35$, or an ODI improvement exceeding 18.8 points. ${ }^{43}$

Mixed effects linear regression was used for repeated continuous measures (VAS SIJ pain, ODI, EQ-5D and SF-36). The number of adverse events per subject was compared across groups with Poisson regression. Subject satisfaction levels were compared using proportional odds logistic regression. The change in the proportion of subjects using opioids was calculated using McNemar's test and a conditional log odds ratio was calculated to compare these changes across groups. The relationship between baseline predictors and mean responses was evaluated using simple or repeated measures analysis of variance. Confidence intervals for proportions were determined using the method of Clopper and Pearson. ${ }^{44}$ All statistical analyses were performed using $R .^{45}$ The study manuscript was written jointly by study investigators and the sponsor; statistical analyses were completed by the sponsor. Datasets will be made available through Yale's Open Data Access (YODA) program. ${ }^{46}$

\section{Results}

Screening, enrollment and randomization. Of the
442 patients who were screened for participation at 19 sites, 159 (37.8\%) were enrolled. Eleven subjects withdrew before treatment ( 1 before randomization and 10 after randomization but before any treatment was performed), yielding a total of 148 subjects who were enrolled, randomized and treated (102 to SIJF and 46 to NSM).

Baseline characteristics. Subject characteristics were similar across assignment groups (Table 1). Mean subject age was 51.3 years; $12.2 \%$ (18 subjects) were 65 years of age or older. The majority (95.3\%) of subjects were Caucasian and 103 (69.6\%) were women. Subjects were highly debilitated by SIJ pain as indicated by high baseline pain ratings (mean 82.3 on the 0-100 scale) and ODI scores (mean 56.8).

Nineteen percent were not working due to chronic pain. The duration of pain prior to enrollment averaged 6.4 years (range $0.5-40.7$ years); $87.2 \%$ had pain for $\geq 1$ year and $73.6 \%$ had pain for $\geq 2$ years. Pain locations reported by subjects were largely centered over the posterior superior iliac spine, but distant pain and pain radiating anteriorly or posteriorly were also frequent. A substantial proportion of subjects (39.2\%) had undergone prior lumbar fusion, $14.9 \%$ had been diagnosed with lumbar stenosis, $12.8 \%$ had concomitant hip disorders, and 7.4\% had sustained previous sacral trauma. The majority of trial subjects had undergone SIJ-specific physical therapy (72.3\%) and SIJ steroid injections (85.8\%); a minority (16.9\%) had undergone prior $\mathrm{RF}$ ablation of the sacral nerve root lateral branches. About two-thirds (66.9\%) were taking opioid pain medications at baseline and every subject reported that multiple activities commonly caused or worsened their SIJ pain. Quality of life (QOL) was substantially diminished, as reflected by low EQ-5D time trade-off (TTO) scores (mean of 0.45) and low SF-36 scores (mean physical component summary [PCS] score of 30.4 and mean mental component summary [MCS] score of 43.1), confirming that SIJ dysfunction is associated with a significant burden of disease. ${ }^{14}$ 
Table 1. Characteristics of enrolled subjects.

\begin{tabular}{|c|c|c|c|}
\hline Characteristic & $\begin{array}{r}\text { Non-Surgical Management } \\
(n=46)\end{array}$ & $\begin{array}{r}\text { SIJ Fusion } \\
(n=102)\end{array}$ & P-value* \\
\hline Age, mean (SD, range) & $53.8(29.5-71.1)$ & $50.2(25.6-71.7)$ & 00627 \\
\hline$\geq 65$ years old, n (\%) & $8(17.4 \%)$ & $10(9.8 \%)$ & 0.0021 \\
\hline Women, n (\% female) & $2860.9 \%$ & $75(73.5 \%)$ & 0.1279 \\
\hline \multicolumn{4}{|l|}{ Race, n (\%) } \\
\hline White & $44(95.7 \%)$ & $97(95.1 \%)$ & \multirow{4}{*}{0.8344} \\
\hline Black & $2(4.3 \%)$ & $3(2.9 \%)$ & \\
\hline American Indian & $0(0.0 \%)$ & $1(1.0 \%)$ & \\
\hline Other & $0(0.0 \%)$ & $1(1.0 \%)$ & \\
\hline Ethnicity & & & 0.2552 \\
\hline Hispanic or Latino, $\mathrm{n}(\%)$ & $4(8.7 \%)$ & $4(3.9 \%)$ & 0.2532 \\
\hline Body mass index, mean (range) & $30.6(19.4-48.9)$ & $30.4(16.7-49.5)$ & 0.8331 \\
\hline \multicolumn{4}{|l|}{ Smoking status, n (\%) } \\
\hline Current smoker & $3(6.5 \%)$ & $26(25.5 \%)$ & \multirow{3}{*}{0.0117} \\
\hline Former smoker & $13(28.3 \%)$ & $30(29.4 \%)$ & \\
\hline Never smoker & $30(65.2 \%)$ & $46(45.1 \%)$ & \\
\hline Ambulatory without assistance (n, \%) & $41(89.1 \%)$ & $89(87.3 \%)$ & 1.0000 \\
\hline \multicolumn{4}{|l|}{ Work status (n, \%) } \\
\hline Working full-time & $21(45.7 \%)$ & $45(44.1 \%)$ & \multirow{6}{*}{0.9850} \\
\hline Working part time & $4(8.7 \%)$ & $9(8.8 \%)$ & \\
\hline Not working, student & $0(0.0 \%)$ & $1(1.0 \%)$ & \\
\hline Not working, retired & $9(19.6 \%)$ & $21(20.6 \%)$ & \\
\hline Not working due to back pain & $8(17.4 \%)$ & $20(19.6 \%)$ & \\
\hline Not working other reason & $4(8.7 \%)$ & $6(5.9 \%)$ & \\
\hline Prior lumbar fusion (n, \%) & $17(37.0 \%)$ & $41(40.2 \%)$ & 0.8558 \\
\hline \multicolumn{4}{|l|}{ Underlying diagnosis } \\
\hline Degenerative sacroiliitis & $40(87.0 \%)$ & $88(86.3 \%)$ & 1.0000 \\
\hline Sacroiliac joint disruption & $6(13.0 \%)$ & $14(13.7 \%)$ & \\
\hline Years of pain, mean (range) & $5.0(0.5-38.9)$ & $7.0(0.5-40.7)$ & 0.1037 \\
\hline
\end{tabular}

Downloaded from http://ijssurgery.com/ by guest on April 26, 2023 


\begin{tabular}{|c|c|c|c|}
\hline Characteristic & $\begin{array}{r}\text { Non-Surgical Management } \\
(n=46)\end{array}$ & $\begin{array}{r}\text { SIJ Fusion } \\
(\mathrm{n}=102)\end{array}$ & P-value* \\
\hline \multicolumn{4}{|l|}{ Pain syndrome } \\
\hline Pain began peripartum & $19(41.3 \%)$ & $29(28.4 \%)$ & 0.2710 \\
\hline Pain radiates down leg & $41(89.1 \%)$ & $89(87.3 \%)$ & 1.0000 \\
\hline Groin pain & $29(63.0 \%)$ & $60(58.8 \%)$ & 0.7177 \\
\hline Pain worse with sitting & $41(89.1 \%)$ & $89(87.3 \%)$ & 1.0000 \\
\hline Pain worse with rising & $41(89.1 \%)$ & $88(86.3 \%)$ & 0.7926 \\
\hline Pain worse with walking & $42(91.3 \%)$ & $87(85.3 \%)$ & 0.4285 \\
\hline Pain worse with climbing stairs & $41(89.1 \%)$ & $93(91.2 \%)$ & 0.7638 \\
\hline Pain worse descending stairs & $37(80.4 \%)$ & $82(80.4 \%)$ & 1.0000 \\
\hline \multicolumn{4}{|l|}{ Prior treatments } \\
\hline Physical therapy & $36(78.3 \%)$ & $71(69.6 \%)$ & 0.3247 \\
\hline Steroid SIJ injection & $42(91.3 \%)$ & $85(83.3 \%)$ & 0.3082 \\
\hline RF ablation & $4(8.7 \%)$ & $21(20.6 \%)$ & 0.0972 \\
\hline Taking opioids (n, \%) & $29(63.0 \%)$ & $70(68.6 \%)$ & 0.6317 \\
\hline Proportion with lumbar stenosis (n, \%) & $7(15.2 \%)$ & $15(14.7 \%)$ & 1.0000 \\
\hline Proportion with hip diagnosis (n, \%) & $3(6.5 \%)$ & $16(15.7 \%)$ & 0.1837 \\
\hline Proportion with sacral trauma (n, \%) & $3(6.5 \%)$ & $8(7.8 \%)$ & 1.0000 \\
\hline VAS SIJ pain score, mean $( \pm \mathrm{SD})$ & $82.2(9.9)$ & $82.3(11.9)$ & 0.9280 \\
\hline ODI score, mean $( \pm \mathrm{SD})$ & $56.0(14.0)$ & $57.2(12.8)$ & 0.6328 \\
\hline \multicolumn{4}{|l|}{ SF-36, mean $( \pm$ SD) } \\
\hline PCS & $30.8(6.1)$ & $30.2(6.2)$ & 0.5709 \\
\hline MCS & $43.3(12.1)$ & $43.0(11.5)$ & 0.8624 \\
\hline \multicolumn{4}{|l|}{ EQ-5D } \\
\hline TTO index & $0.47(0.19)$ & $0.44(0.18)$ & 0.3376 \\
\hline Health Thermometer & $57.8(22.9)$ & $53.2(23.8)$ & 0.2776 \\
\hline
\end{tabular}


Subject trial flow. Of 148 randomized and treated subjects, 6-month follow-up (at which time the primary endpoint was determined) was obtained in 101/ 102 (99\%) of subjects treated with SIJF and 44/46 (95.7\%) of subjects treated with NSM (Figure 1). 24-month follow-up was obtained in 89 (87.3\%) SIJF subjects. Subjects who had crossed over (see below) are continuing to be evaluated, so long-term outcomes in this group are not the focus of this report.
In the SIJF group, 13 subjects withdrew prior to month 24. Nine were lost to follow up despite multiple efforts to contact them, 1 was withdrawn by the site PI for drug-seeking behavior, 2 were withdrawn as a result of site termination from the study, and 1 died due from a fatal myocardial infarction. One site was terminated after 12-month subject visits were complete due to persistent non-compliance with the study protocol. 


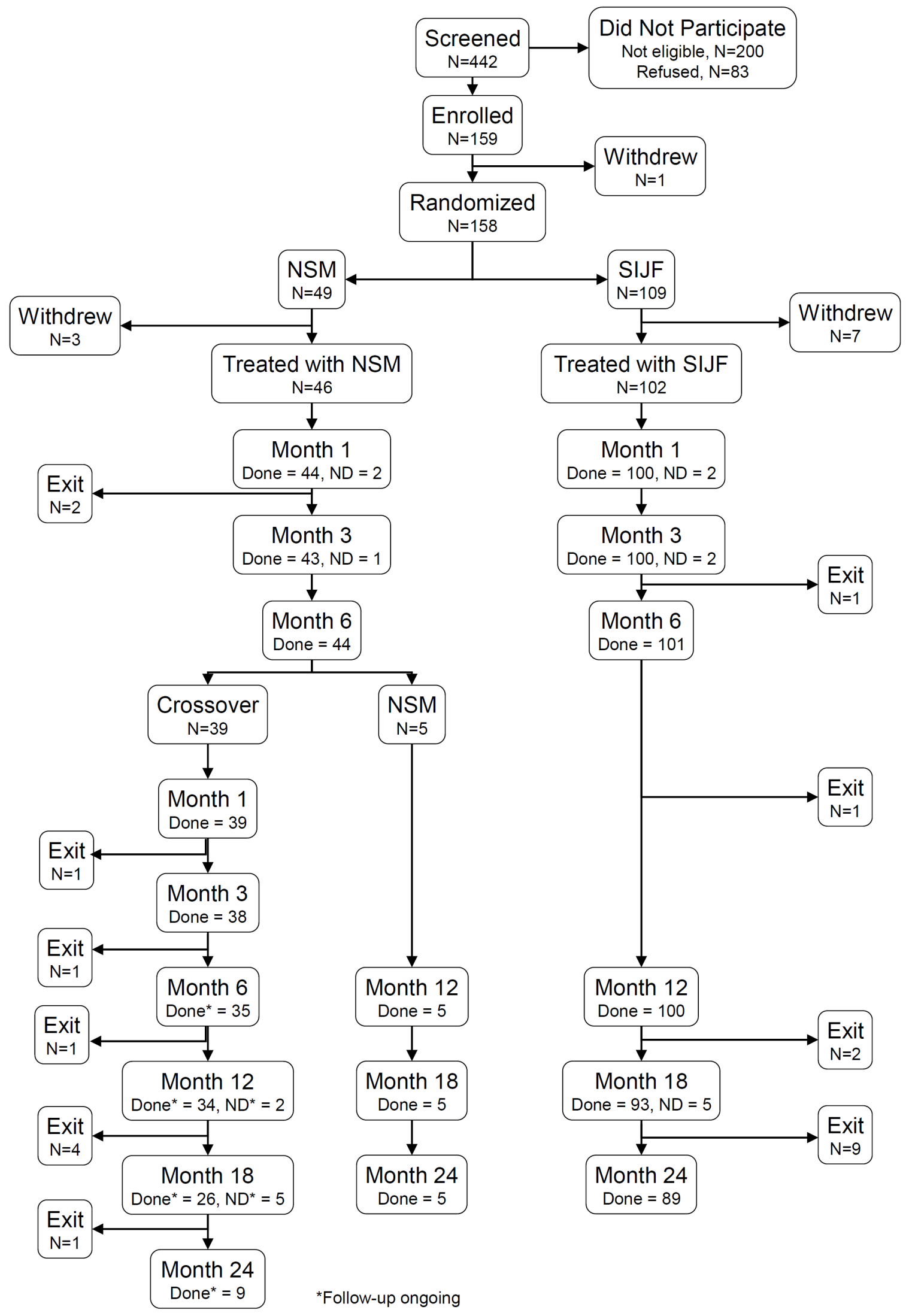

Fig. 1. Subject flow. 
Procedure characteristics. 102 subjects underwent SIJF (78 unilateral, 24 planned bilateral). For the index procedure, the mean procedure time was 44.9 minutes (range 14-140 minutes, Table 2). Mean fluoroscopy time was 2.5 minutes (range 0.13-25.4 minutes). Mean estimated blood loss was $32.7 \mathrm{cc}(90.2 \%$ had blood loss $\leq 50 \mathrm{cc}$ and only 1 subject had blood loss $>100 \mathrm{cc}$ ) and no subject required a transfusion. Three implants were used in most (91.2\%) cases and nearly all (99.3\%) implants were $7 \mathrm{~mm}$ in diameter. Median hospital length of stay ranged was 1 day (range 0-7 days). Three prolonged hospital stays ( $\geq 3$ days, $2.9 \%$ ) were related to subject comorbidities and not device- or procedure-related adverse events.

Non-surgical management. Of the 46 subjects randomized to NSM, all but 1 received PT during the six months after treatment assignment, 34 (73.9\%)

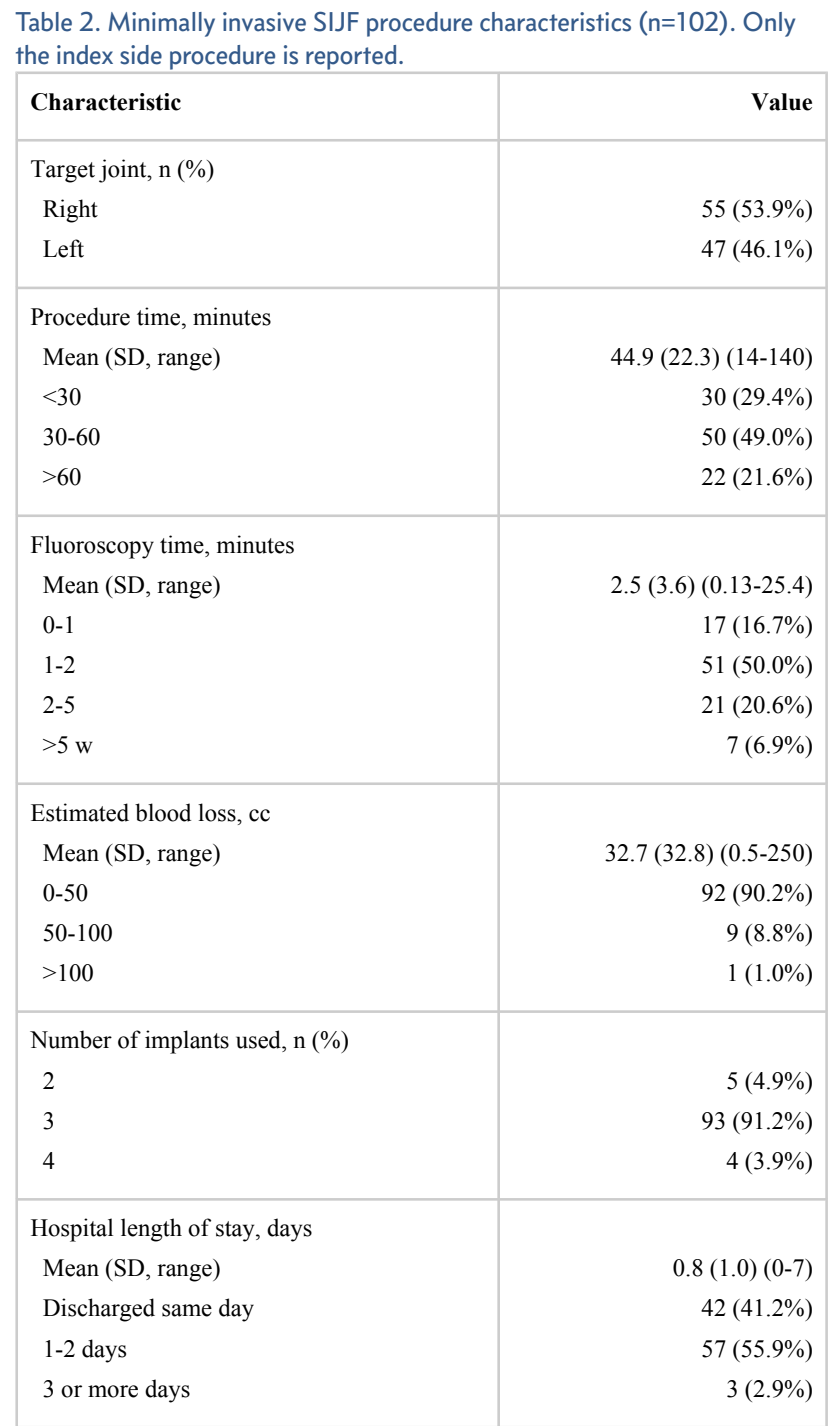

underwent at least one steroid injection (6 subjects underwent 2 injections) and 21 (45.7\%) underwent at least one radiofrequency ablation of the sacral nerve root branches. Forty (87.0\%) NSM subjects underwent at least 2 types of NSM treatments in addition to the use of pain medications.

Primary endpoint. By month 6, 84 of 102 SIJF subjects $(82 \%, 95 \%$ posterior credible interval $[\mathrm{CI}]$ $74-89 \%)$ and 12 of 46 NSM subjects $(26 \%, 14-41 \%)$ met the study's primary success endpoint. In the SI$\mathrm{JF}$ group, one subject was a failure for the 6-month primary endpoint due to both inadequate pain relief and immediate revision required for symptomatic implant malposition. In the NSM group, all primary endpoint failures were as a result of inadequate pain relief. The intent-to-treat difference in success rates was 55\% (95\% CI 40-69\%), representing a $>3$-fold difference in success rate, and the posterior probability that the success rate was higher in the SIJF group was $>0.9999$. Pre-specified subgroup analysis (Table 3) showed similar differences between success rates associated with SIJF and NSM according to underlying diagnosis, a history of prior lumbar fusion, smoking status or unilateral vs. bilateral SIJ pain.

Secondary endpoints. In the SIJF group, the mean SIJ pain score improved from 82.3 at baseline to 30.1 at 6 month follow-up, 28.6 at 12 months and 26.7 at 24 months, corresponding to improvements from baseline of 52.3, 53.7and 55.4 points, respectively (all $\mathrm{p}<.0001$, Figure 2). In the NSM group, mean SIJ pain improved from 82.2 to 70.3 at 6 months (12.2-point improvement). Combining all time points up to month 6, the improvement in VAS SIJ improvement was 38.2 points greater for the SIJF group compared to the NSM group ( $\mathrm{p}<.0001$, repeated measures analysis of variance). In the SIJF group, mean ODI decreased from 57.2 at baseline to 29.9, 28.3 and 28.7 at months 6,12 and 24 , representing improvements of 27.4, 28.9 and 28.4 points, respectively $(\mathrm{p}<.0001)$. In the NSM group, mean ODI decreased by only 4.6 points at 6 months $(\mathrm{p}=0.0537)$.

Crossover. No early crossover (i.e., before that allowed by the protocol at month 6) occurred in the NSM group. After the 6-month visit, 39 of 44 (89\%) NSM subjects who were still participating crossed 
over to surgical treatment, and all crossover procedures were SIJF using the study device. Compared to those who did not cross over, the crossover subjects had higher pain (Figure 2, top) and ODI scores (Figure 2, bottom) at month 6 . After the crossover surgery procedures, both SIJ pain and ODI scores improved in a fashion similar to those originally assigned to SIJF. Subjects who did not cross over did not show continued improvement in pain or ODI scores at 2-year follow-up.

Substantial clinical benefit. Table 4 shows the proportions of subjects who had threshold improvements from baseline in VAS SIJ pain or ODI scores as a result of the assigned treatment only. In those assigned to SIJF, $79.2 \%$ at month 6 and $82.0 \%$ at month 24 met the substantial pain improvement threshold and $62.4 \%$ and $65.9 \%$, respectively, met the ODI substantial improvement threshold. The proportion of NSM subjects meeting these thresholds was less than $10 \%$.
Quality of life. At 6,12 and 24 months, the mean EQ-5D TTO index had improved in the SIJF group by $0.29,0.31$ and 0.28 points, respectively $(\mathrm{p}<.0001$, Figure 3). In the NSM group, EQ-5D TTO improvement at 6 months was minimal (mean 0.06 points, $\mathrm{p}=0.1740, \mathrm{p}<.0001$ for difference in change score vs. SIJF). Likewise, at 6, 12 and 24 months, the mean SF-36 PCS score improved in the SIJF group by 12.5, 12.8 and 11.2 points, respectively $(\mathrm{p}<.0001)$, larger than the 6-month changes observed in the NSM group (mean 3.9 points, $\mathrm{p}=.2990, \mathrm{p}<.0001$ for difference in change score vs. SIJF). The improvements in EQ-5D TTO and SF-36 PCS after crossover surgery were similar to those observed in the group originally assigned to SIJF.

Success predictors in NSM. Of interest were prerandomization characteristics in the NSM cohort that were associated with score improvements at 6 months. Analysis showed two factors that predicted smaller VAS SIJ pain improvements in the NSM

Table 3. Six-month success rates and subgroup analysis. Each cell shows number of successes / number treated, success rate and $95 \%$ posterior credible intervals in parentheses.

\begin{tabular}{|c|c|c|c|c|}
\hline Subgroup & Level & SIJ Fusion & NSM & Rate Difference* \\
\hline \multirow{2}{*}{ Diagnosis } & Degenerative sacroiliitis & $\begin{array}{l}71 / 88,80.7 \% \\
(70.9-88.3 \%)\end{array}$ & $\begin{array}{l}11 / 40,27.5 \% \\
(14.6-43.9 \%)\end{array}$ & $\begin{array}{l}52.3 \% \\
(35.6-67.2 \%)\end{array}$ \\
\hline & Sacroiliac joint disruption & $\begin{array}{l}13 / 14,92.9 \% \\
(66.1-99.8 \%)\end{array}$ & $\begin{array}{l}1 / 6,16.7 \% \\
(0.4-64.1 \%)\end{array}$ & $\begin{array}{l}68.5 \% \\
(31.0-93.1 \%)\end{array}$ \\
\hline \multirow{2}{*}{ History of lumbar fusion } & Yes & $\begin{array}{l}35 / 41,85.4 \% \\
(70.8-94.4 \%)\end{array}$ & $\begin{array}{l}3 / 17,17.6 \% \\
(3.8-43.4 \%)\end{array}$ & $\begin{array}{l}65.1 \% \\
(41.8-83.0 \%)\end{array}$ \\
\hline & No & $\begin{array}{l}49 / 61,80.3 \% \\
(68.2-89.4 \%)\end{array}$ & $\begin{array}{l}9 / 29,31.0 \% \\
(15.3-50.8 \%)\end{array}$ & $\begin{array}{l}48.2 \% \\
(28.0-66.1 \%)\end{array}$ \\
\hline \multirow{3}{*}{ Smoking } & Current & $\begin{array}{l}20 / 26,76.9 \% \\
(56.4-91.0 \%)\end{array}$ & $\begin{array}{l}1 / 3,33.3 \% \\
(0.8-90.6 \%)\end{array}$ & $\begin{array}{l}38.5 \% \\
(0-76.7 \%)\end{array}$ \\
\hline & Never & $\begin{array}{l}39 / 46,84.8 \% \\
(71.1-93.7 \%)\end{array}$ & $\begin{array}{l}7 / 30,23.3 \% \\
(9.9-42.3 \%)\end{array}$ & $\begin{array}{l}59.8 \% \\
(40.4-76.4 \%)\end{array}$ \\
\hline & Former & $\begin{array}{l}25 / 30,83.3 \% \\
(65.3-94.4 \%)\end{array}$ & $\begin{array}{l}4 / 13,30.8 \% \\
(9.1-61.4 \%)\end{array}$ & $\begin{array}{l}50.1 \% \\
(21.2-74.7 \%)\end{array}$ \\
\hline \multirow{2}{*}{ Bilateral pain } & Yes & $\begin{array}{l}28 / 36,77.8 \% \\
(60.8-89.9 \%)\end{array}$ & $\begin{array}{l}2 / 12,16.7 \% \\
(2.1-48.4 \%)\end{array}$ & $\begin{array}{l}57.8 \% \\
(30.1-78.8 \%)\end{array}$ \\
\hline & No & $\begin{array}{l}56 / 66,84.8 \% \\
(73.9-92.5 \%)\end{array}$ & $\begin{array}{l}10 / 34,29.4 \% \\
(15.1-47.5 \%)\end{array}$ & $\begin{array}{l}54.3 \% \\
(36.1-70.5 \%)\end{array}$ \\
\hline All & & $\begin{array}{l}84 / 102,82.4 \% \\
(73.6-89.2 \%)\end{array}$ & $\begin{array}{l}12 / 46,26.1 \% \\
(14.3-41.1 \%)\end{array}$ & $\begin{array}{l}55.4 \% \\
(40.1-69.1 \%)\end{array}$ \\
\hline
\end{tabular}

*Point estimate ( $95 \%$ posterior credible interval). 
group: a history of lumbar fusion (14 points less improvement, $\mathrm{p}=0.0582)$, narcotic use at baseline (17 points less improvement, $\mathrm{p}=0.0200)$. Other factors were not predictive of VAS SIJ pain changes: bilateral symptoms, underlying diagnosis (degeneration vs. disruption), body mass index, age, response to SIJ block, pain beginning in the peripartum period, and smoking. Only narcotic use at baseline was predictive of smaller ODI improvements at month 6 (by 9.3 points, $\mathrm{p}=0.0556$ ).
Success predictors in SIJF. Using repeated measures analysis of variance, the following were not statistically significant predictors of pain improvements: bilaterality of treatment, history of lumbar fusion, underlying condition, smoking status, opioid use at baseline, pain beginning in the peripartum period, age and body mass index category. Higher average acute pain reduction during an SIJ block did not predict higher responses to SIJ fusion. Similar findings were observed for ODI.
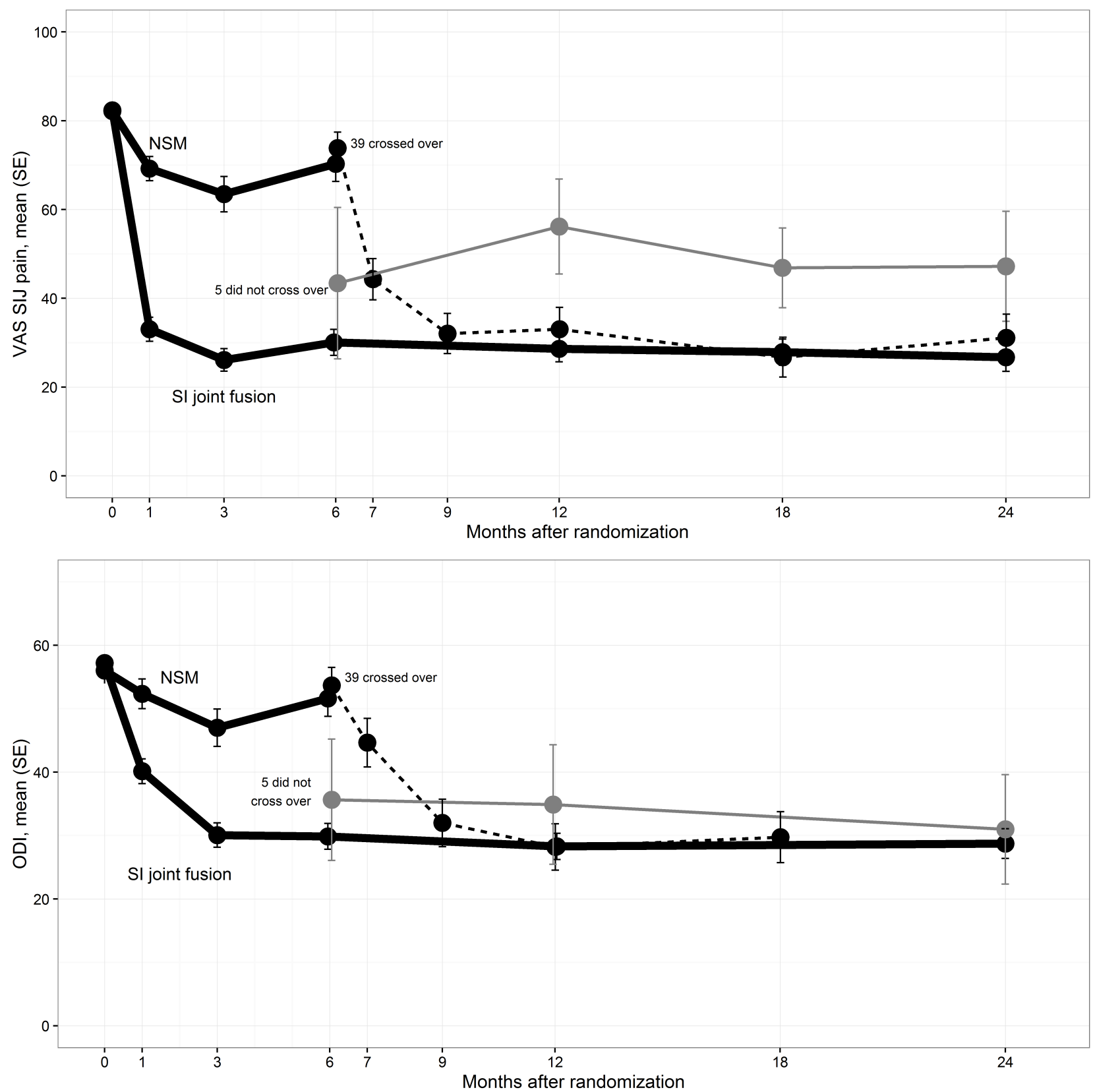

Fig. 2. Mean SIJ pain by visit (top). Dark thick lines are those assigned to NSM or SIJF. Dotted line indicates NSM subjects who crossed over to surgery. Thin gray line indicates those who did not cross over to surgery. Mean Oswestry Disability Index by visit (bottom) is shown similarly. 
Satisfaction rates. Six-month satisfaction rates were higher in the SIJF group compared to the NSM group $(77.2 \%$ vs. $27.3 \%$ very satisfied, $\mathrm{p}<.0001$, proportional odds logistic regression). These rates remained high at 12 and 24 months following surgery (78.0\% and 73.3\%). The proportions of SIJF subjects who would definitely have the procedure again were $79.2 \%, 75.0 \%$ and $71.1 \%$ at 6,12 and 24 months, respectively.

Opioid use. At baseline, $68.6 \%$ and $63.0 \%$ of SIJF and NSM subjects were taking 1 or more opioid analgesics for SIJ or lower back pain, respectively. By month 6 , the proportions were $58.4 \%$ and $70.5 \%$ (Figure 4), representing a $9 \%$ decrease in use for the fusion group and a 7.5\% increase in the NSM group. By month 24, the proportion of SIJF subjects taking opioids reduced to $48.3 \%$ (a 29.6\% reduction, $\mathrm{p}=0.0108$ for change, McNemar's test). Of those who crossed over, a similar proportion (55.9\%) were taking opioids 12 months after crossover.

Adverse events. Adverse events occurred with similar frequency in the first 180 days ( 1.5 per SIJF subject vs. 1.3 per NSM subject, $\mathrm{p}=0.2253) .22$ events were related to the device or SIJF procedure (Table 5). Events included neuropathic symptoms ( $\mathrm{n}=1,1$ case directly attributed to the iFuse implant itself), postoperative medical problems $(n=4$, including urinary retention (1 case), nausea/vomiting ( 2 cases) and atrial fibrillation (1 case)), ipsilateral or contralateral SIJ pain and trochanteric bursitis $(n=9)$, surgical wound problems $(n=5$, drainage, hematoma, infec- tion, stitch abscess and delayed wound healing, 1 case each), iliac fracture ( $\mathrm{n}=1)$ and asymptomatic physical exam or radiographic findings $(\mathrm{n}=2) .5$ events were ongoing, primarily continued pain. 4 subjects randomized to iFuse experienced events probably or definitely related to other procedures for SIJ pain, including postoperative neuropathy after a revision surgery (see below); back pain related to PT, L5 radiculopathy related to a selective nerve root block and worsening back pain possibly related to facet arthropathy. 5 NSM subjects had adverse events related to NSM, including 1 case each of increased SIJ pain, SIJ pain due to PT, back pain due to PT, SIJ pain related to a steroid injection, and flushing and shortness of breath related to an SIJ steroid injection.

Revision surgeries. Three subjects assigned to SIJF and one subject who underwent SIJF as a crossover treatment underwent revision surgery during the follow-up period. One subject had implant-related impingement on a sacral nerve root requiring immediate revision, and the pain resolved promptly following reposition of the device. Two additional subjects assigned to SIJF underwent revision, one at day 428 related to suboptimal device position, and one at day 661 for treatment of a hairline fracture of the ipsilateral ilium adjacent to the most caudal implant which was evident on CT. In this last case, the subject recalled possibly injuring her pelvis while lifting a heavy object but no formal treatments were initiated; she was feeling well and had returned to high levels of activity until she began to experience buttock pain

Table 4. Threshold-level improvements in VAS SIJ pain and ODI attributable to the assigned treatment over time.

\begin{tabular}{|c|c|c|c|c|c|c|c|c|}
\hline \multirow[b]{3}{*}{ Months } & \multicolumn{4}{|l|}{ VAS SIJ Pain } & \multicolumn{4}{|l|}{ ODI } \\
\hline & \multicolumn{2}{|c|}{$\begin{array}{l}\text { Improvement } \geq 20 \text { Points, } \\
t / n(\%)^{*}\end{array}$} & \multicolumn{2}{|c|}{$\begin{array}{l}\text { Improvement } \geq 25 \text { Points or Rating } \leq 35 \text { points, } \\
t / n(\%)\end{array}$} & \multicolumn{2}{|c|}{$\begin{array}{l}\text { Improvement } \geq 15 \text { Points, } \\
\text { t/n (\%) }\end{array}$} & \multicolumn{2}{|c|}{$\begin{array}{l}\text { Improvement } \geq 18.8 \text { points, } \\
\text { t/n (\%) }\end{array}$} \\
\hline & SIJF & NSM & SIJF & NSM & SIJF & NSM & SIJF & NSM \\
\hline 1 & $84 / 100(84.0 \%)$ & $13 / 45(28.9 \%)$ & $79 / 100(79.0 \%)$ & $11 / 45(24.4 \%)$ & $49 / 100(49.0 \%)$ & $6 / 45(13.3 \%)$ & $44 / 100(44.0 \%)$ & $3 / 45(6.7 \%)$ \\
\hline 3 & $87 / 100(87.0 \%)$ & $17 / 43(39.5 \%)$ & $84 / 100(84.0 \%)$ & $13 / 43(30.2 \%)$ & $72 / 100(72.0 \%)$ & $13 / 43(30.2 \%)$ & $64 / 100(64.0 \%)$ & $10 / 43(23.3 \%)$ \\
\hline 6 & $84 / 101(83.2 \%)$ & $12 / 43(27.9 \%)$ & $80 / 101(79.2 \%)$ & $8 / 43(18.6 \%)$ & $74 / 101(73.3 \%)$ & $6 / 44(13.6 \%)$ & $63 / 101(62.4 \%)$ & $5 / 44(11.4 \%)$ \\
\hline 12 & $81 / 100(81.0 \%)$ & $4 / 40(10 \%)$ & $79 / 100(79.0 \%)$ & $3 / 40(7.5 \%)$ & $72 / 100(72.0 \%)$ & $3 / 40(7.5 \%)$ & $66 / 100(66.0 \%)$ & $2 / 40(5 \%)$ \\
\hline 24 & $74 / 89(83.1 \%)$ & $4 / 40(10 \%)$ & $73 / 89(82.0 \%)$ & $4 / 40(10 \%)$ & $60 / 88(68.2 \%)$ & $3 / 40(7.5 \%)$ & $58 / 88(65.9 \%)$ & $3 / 40(7.5 \%)$ \\
\hline
\end{tabular}

* $\mathrm{t}=$ number who had threshold change, $\mathrm{n}=$ number evaluated. 
acutely during a running race approximately 18 months after index SIJF. A CT showed loosening of implants in the sacrum and a repeat SIJ block was positive. The subject underwent revision surgery, removing 2 of the 3 placed implants, inserting another SIJF fusion system implant and bone grafting of the joint via posterior muscle splitting approach using a fixed tubular retractor; this surgery was complicated by the development of a S1 radiculopathy which required yet another revision surgery. Finally, another subject who underwent SIJF as a crossover surgery experienced postoperative radicular pain which also necessitated SIJ revision surgery consisting of repositioning the offending implant; however, a CT myelogram showing moderate bilateral foraminal stenosis at L4-L5 and L5-S1 which could represent a potential alternative explanation for the persistent radicular pain.

Event severity. Seventy-eight adverse events were deemed severe in nature by the investigator ( 55 in the SIJF group and 23 in the NSM group). In the SIJF
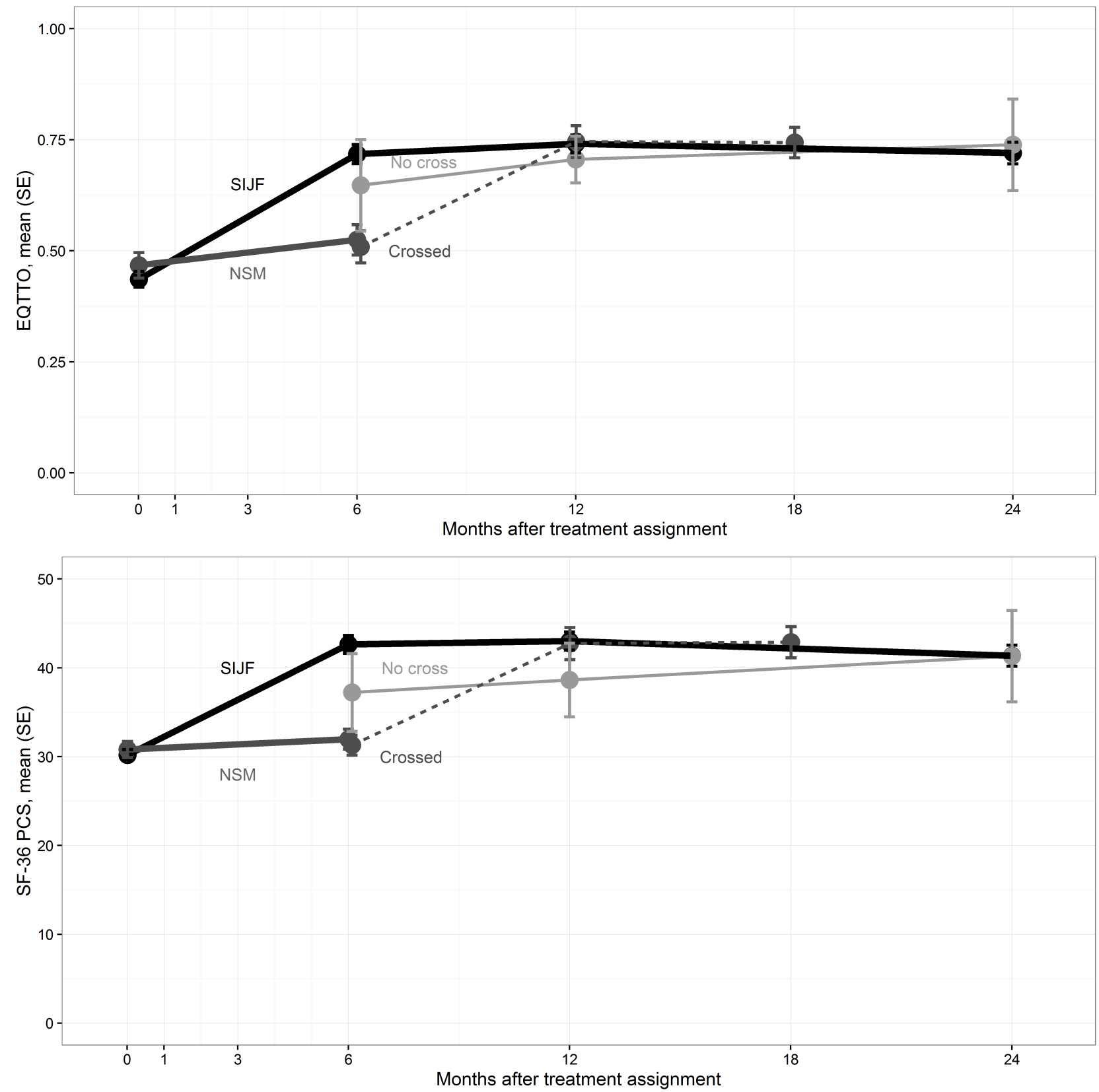

Fig. 3. Change in EQ-5D time tradeoff index (top) and SF-36 PCS (bottom) by visit. Lines are annotated similar to Figure 2. 
group, 5 of the 55 severe events were procedure- or device-related: one case each of postoperative atrial fibrillation, neuropathic pain due to implant malposition, wound hematoma, and ilial fracture related to an implant (described above) and SIJ pain related to physical activity and loosening (described above). All other events were unrelated to the SIJ. Two subjects died from causes unrelated to the SIJ: one from pulmonary fibrosis and chronic obstructive pulmonary disease and one from a fatal myocardial infarction.

\section{Discussion}

In our randomized trial, subjects with chronic SIJ

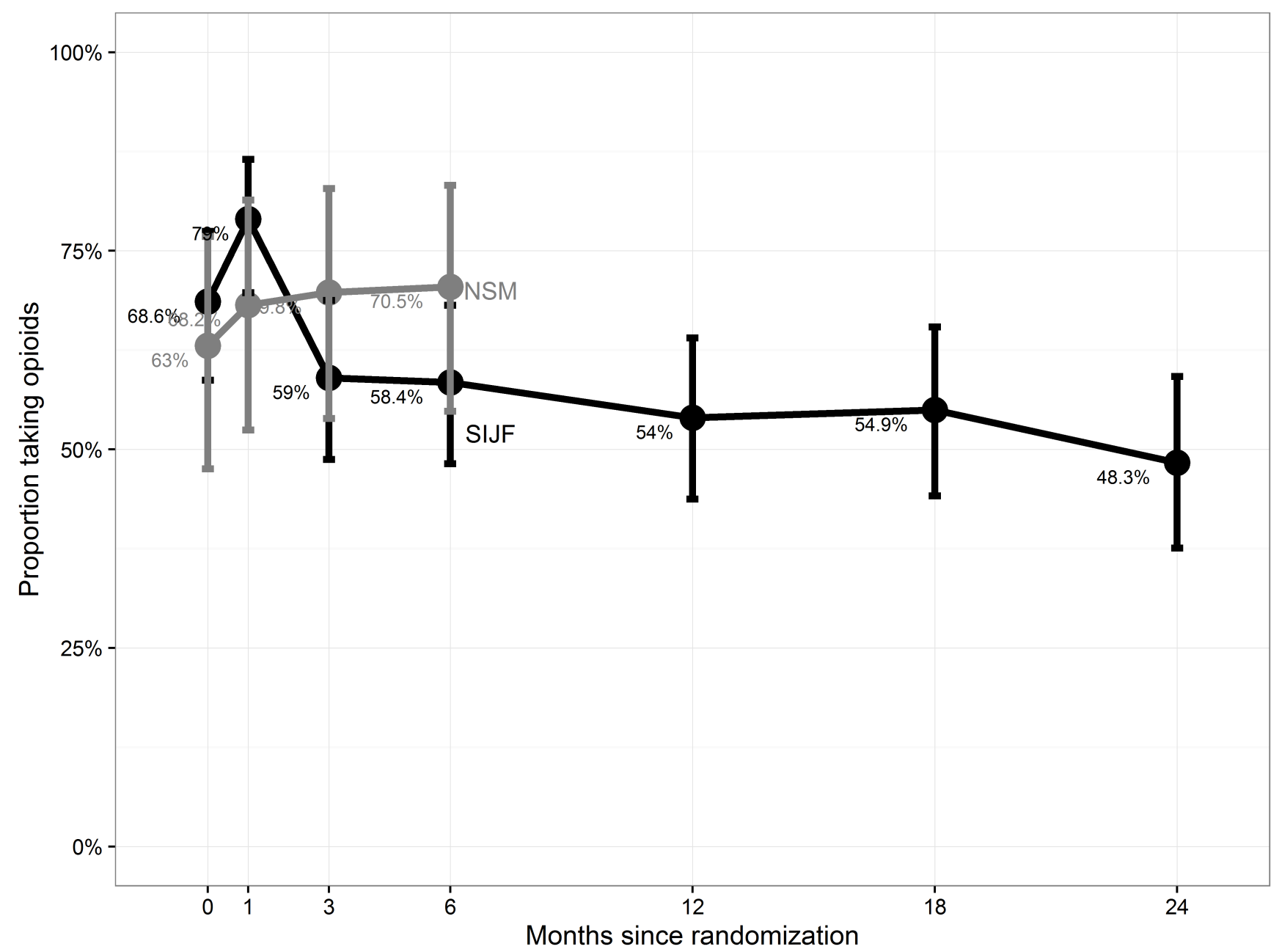

Fig. 4. Proportion of subjects reporting opioid use at each study visit.

Table 5. Adverse events related to device or procedure in SIJF group ( $n=102$ subjects).

\begin{tabular}{|l|r|}
\hline Event Type & N (\%)* \\
\hline Finding** & $2(2 \%)$ \\
Fracture & $1(1 \%)$ \\
Neuropathy & $1(1 \%)$ \\
Pain & $9(9 \%)$ \\
Post-operative*** & $4(4 \%)$ \\
Wound & $5(5 \%)$ \\
Total & $22(23 \%)$ \\
\hline
\end{tabular}

*Percent reported as number of events divided by number assigned to treatment. **Physical examination or radiographic finding. ***Postoperative issue, such as urinary retention, nausea/vomiting, atrial fibrillation.

Downloaded from http://ijssurgery.com/ by guest on April 26, 2023 
pain assigned to minimally invasive SIJF showed statistically significant and clinically meaningful improvements in SIJ pain, disability (as measured by ODI) and quality of life (as measured by both EQ-5D and SF-36). At 24 months, the proportion of subjects achieving significant clinical benefit ${ }^{43}$ from the assigned treatment was high in the SIJF group $(82.0 \%$ for pain improvement and $65.9 \%$ for ODI improvement) but low in the NSM group ( $<10 \%$ each). Although SIJF did not completely alleviate pain and disability, the improvements observed were substantial and clinically important for this patient population.

The 6-month changes in pain, disability and quality of life observed in our study were very similar to those reported in a European randomized trial of similar design. ${ }^{47}$ Moreover, the 2-year improvements in our study were very similar to those observed in a 2-year prospective single-arm clinical trial with identical enrollment criteria and assessments. ${ }^{48}$ Further validating this study is the finding that subjects who crossed over from NSM to SIJF after the 6-month visit obtained benefits similar to those originally assigned to SIJF. Although the study follow-up was limited to two years, improvements of longer durations have been reported in case series of $3,{ }^{49} 4^{13}$ and 5 years. $^{29}$

The improvements after SIJF documented in our study are as favorable as those associated with other commonly performed spine surgeries. In our study, $68.2 \%$ of subjects had a 15 or more point improvement in ODI at 2 years, values similar to those observed in patients undergoing lumbar fusion using recombinant human bone morphogenetic protein $\left(83 \%^{50}, 71 \%^{51}\right)$. The mean improvement in ODI in our cohort (28.4 points) was somewhat larger than values observed in the Spine Patient Outcomes Research Trial (SPORT) studies evaluating the surgical treatment of patients with lumbar degenerative spondylolisthesis $\left(24\right.$ points $\left.^{52}\right)$ and lumbar stenosis $(20$ points ${ }^{53}$ ) but smaller than that observed for those undergoing operative intervention for lumbar disc herniation (37.6 points $\left.^{54}\right)$.

The improvements in pain, disability and quality of life observed following SIJF were particularly signifi- cant given the long duration of SIJ pain (on average 6.4 years) and the high rate of failure to respond to prior non-surgical management $(72.3 \%$ had received physical therapy and $85.8 \%$ had received 1 or more SIJ injections). While other spine surgery studies often exclude patients with a history of prior spine surgery, ours included patients who had undergone prior lumbar fusion, which has been recognized as being a risk factor for SIJ degeneration. ${ }^{4}$ However, we observed no differences between the long-term outcomes of those with and without a history of prior lumbar fusion. Taken together, our study, combined with 2 other prospective trials ${ }^{47,48}$ and published case series, provides substantial evidence that supports the safety and effectiveness of minimally invasive SIJF using triangular titanium implants.

In contrast to the experience of those treated with SI$\mathrm{JF}$, subjects assigned to NSM generally showed little improvements in pain (12.2 points), disability (4.6 points) and quality of life (0.06 EQ-5D TTO points) at 6 months. While improvements in pain and disability were evident at 1 and 3 months in some NSM subjects, only a small proportion showed substantial improvement by month 6 (18.6\% with substantial improvement in SIJ pain and $11.4 \%$ with substantial improvement in ODI). In this group, individuals not using opioids at baseline were found to have somewhat larger mean improvements in SIJ pain and ODI but the differences were not clinically important. Otherwise there were no other predictors of improvement in the NSM group. We note that statistical power for this type of analysis was limited by the fairly small sample size. Perhaps more importantly, a large proportion of the group assigned to NSM (39 of 44 subjects still participating, $89 \%$ ) crossed over from nonsurgical to surgical treatment, indicating NSM was ineffective at providing substantial pain and disability relief in the majority of these subjects.

Subgroup analysis in the SIJF group showed no baseline predictors of improved pain or disability responses to SIJF with the exception of $\geq 75 \%$ acute reduction in pain at 30 or 60 minutes after an SIJ block, which, in our study, predicted small increases in mean long-term responses to SIJF. Previously we reported that mean responses during an SIJ block were not predictive of responses to $\mathrm{SIJF} ;{ }^{55}$ an additional

Downloaded from http://ijssurgery.com/ by guest on April 26, 2023 
analysis done here, defining a "responder" as a reduction of at least $75 \%$ at 30 or 60 minutes, showed statistically significant but clinically unimportant differences in pain and disability responses across responder groups.

The mechanism of action for the device we used (triangular titanium implants) includes short-term stabilization followed by long-term fusion. ${ }^{29}$ The implants used are designed to resist rotational motion (triangular shape) and have a porous titanium surface. Devices with titanium porous surfaces are designed to promote biological fixation and have shown excellent implant survivorship rates in hip implants. ${ }^{56-58}$

In the SIJF group, opioid use decreased by $29.6 \%$, probably as a result of improved pain control, but increased (at 6 months) in the NSM group. We note that our study did not include any treatments (counseling, behavioral techniques, etc.) specifically aimed at opioid use reduction. In theory, such interventions could further reduce opioid use. Reductions might have been limited by concomitant pain in other body locations due to the high prevalence of underlying degenerative conditions.

Complications occurred in both the surgical and nonsurgical groups but the total rate of adverse events per subject was not remarkably different across treatment groups at month 6 . In general, the overall complication rate from surgery was modest and typical of what would be expected from such a minimally invasive procedure. Complications that required surgical revision occurred in 3 subjects (3\%) assigned to SIJF and 1 additional subject who underwent SIJF as a crossover procedure.

Previous studies have demonstrated that direct medical expenses associated with NSM are not inconsequential. ${ }^{59,60}$ An analysis of data from the current study shows that the cost-effectiveness of minimally invasive SIJF in this population is favorable and comparable to that reported for knee or hip joint replacement. ${ }^{61}$ Failure to consider the SIJ as a potential source of chronic low back pain could even result in use of inappropriate operative procedures, such as lumbar fusions, in patients with serendipitous and asymptomatic MRI findings of degenerative lumbar spine changes; these surgeries are not only very costly but are also associated with significant morbidity. ${ }^{62}$

Moreover, the indirect costs arising from patients who cannot work because of chronic SIJ pain are even higher; to this end, analysis of data from this study suggests that SIJF may improve worker productivity in this population. ${ }^{63}$ Collectively, these publications provide further evidence indicating that minimally invasive SIJF may also be cost-effective from a societal perspective.

It is important to emphasize that this trial employed a system of triangular titanium implants placed using a lateral transiliac approach. Whether positive results observed in our study will apply to other devices placed laterally (e.g., hollow modular anchor screws $^{9,64}$ ) or posterior surgical approaches ${ }^{65-67}$ is not known. Several other devices are currently FDAcleared in the US for minimally invasive SIJF; to date, no outcome studies have been published for those devices.

Advantages of our study include a direct, randomized controlled comparison of outcomes after surgical or non-surgical management, careful monitoring and source data verification, and long-term (2-year) outcomes. Physician participants were from a variety of settings, and confirmatory diagnostic SIJ block was often performed by yet another set of physicians, a setting which promotes generalizability. While unplanned crossover can mar the interpretation of surgery vs. non-surgery studies, ${ }^{54,68}$ this did not occur in our trial, which allowed for unbiased comparisons at least to month 6 . The two primary disadvantages of our study were a lack of blinding and high crossover rates after 6 months. At the time of trial design, the investigators did not believe that a sham surgery study would be feasible as it would have precluded enrollment within in a reasonable time frame and its applicability to standard surgical practice would be questionable. Consequently, the high crossover rate of subjects assigned to NSM who ultimately elected to proceed with SIJF after month 6 prevents any direct comparison of outcomes after this time point. However, we observed little improvements in all study outcomes in the NSM group at month 6, suggesting that substantial improvement 
thereafter would not have been expected.

\section{Conclusions}

In this multicenter prospective randomized controlled trial, minimally invasive SIJF with triangular titanium implants provided superior clinical outcomes compared to non-surgical management in patients with SIJ dysfunction. The improvements observed after SIJF were durable at 2 years and the implant revision rate was low.

\section{Acknowledgements}

The authors acknowledge the 80 investigators and coordinators in the INSITE Study Group: John Swofford MD, John Cummings MD, James Cole MD, Elizabeth Pertile, Ellen Looney, Patti Hunker, Mary Anne Gfell (Indiana Interventional Pain and Community Hospital, Indianapolis, IN); Clay Frank MD, Jamie Edwards MD, Gordon Mortensen MD, Tracy Mente RN (Wheaton Franciscan Healthcare, Wauwatosa, WI); Scott Kitchel MD, Christopher Miller MD, Gregory Moore MD, Shawn Potts, Brett Barnes (Neurospine Institute, Eugene, OR); Robert Limoni MD, Nilesh Patel MD, Taylor Romdenne, Denise Barnes RN, Nicholas Peterson (Aurora BayCare Medical Center \& Advanced Pain Management, Green Bay, WI); Harry Lockstadt MD, Elaine Wilhite MS, James Farris PA-C (Bluegrass Orthopaedics \& Hand Care, Lexington, KY); Don Kovalsky MD, Laura Pestka RN, Cristy Newman (Orthopaedic Center of Southern Illinois, Mount Vernon, IL); Peter Whang MD, Donna Ann Thomas MD, Bethany Samperi, Stacey Lombardi (Yale University, New Haven, CT); Emily A. Darr MD, John A. Glaser MD, Laura Fields, Jennifer Philp, Monica Baczko (Medical University of South Carolina, Charleston, SC); Charles Harvey, MD, Jason Peterman PA-C, Karim Bouferrache MPAS PA-C, Lori Latham (Riverside Medical Center, Kankakee, IL); Pierce Nunley MD, Andrew Utter MD, Marcus Stone PhD, Norma Rivera, Monicah Jepkemboi, Anthony Juarez (Spine Institute of Louisiana, Shreveport, LA); Jonathan Sembrano MD, Ed Santos MD, David Polly MD, Charles Ledonio MD, Sharon Yson MD (University of Minnesota, Minneapolis, MN); Philip Ploska MD, Terry Price PA (Regenerative Or- thopaedics and Spine Institute, Stockbridge, GA); Michael Oh MD, Gary Schmidt MD, Matthew Yeager (Allegheny General Hospital, Pittsburgh, PA); Merle Stringer MD, Douglas Stringer MD, Carolyn Henderson (Brain \& Spine Center, Panama City, FL); Farshad Ahadian MD, Yu-Po Lee MD, Katie Lam (University of California, San Diego, CA); Gowriharan Thaiyananthan MD, Bryan Oh MD, Navid Farahmand MD, Tungie Williams (Basic Spine, Newport Beach, CA); William Rosenberg MD, Amy Akins RN BSN CCRC, Pamela McCann RN BSN, Jennifer Feeback CCRP (Midwest Division-RMC, LLC,-Research Medical Center, Kansas City, MO); Vikas Patel MD, Scott Laker MD, Venu Akuthota MD, Christopher Cain MD, Evalina Burger MD, Christopher Kleck MD, Claire Cofer, David Calabrese (University of Colorado, $\mathrm{Au}-$ rora, CO); Mark C. Gillespy MD, Sherri Zicker RN (Orthopaedic Clinic of Daytona Beach, Daytona Beach, FL).

The authors also acknowledge the SI-BONE clinical affairs team (Elaine Wilhite, Shira Stone, Denise Law, Corinne Lee, Jeff Price, Steve Scott, Terry Rangole, and Terrill Himmelmann) for help with study conduct and monitoring.

\section{References}

1. Sakamoto N, Yamashita T, Takebayashi T, Sekine M, Ishii S. An electrophysiologic study of mechanoreceptors in the sacroiliac joint and adjacent tissues. Spine. 2001;26(20):E468-471.

2. Szadek KM, Hoogland PV, Zuurmond WW, de Lange JJ, Perez RS. Nociceptive nerve fibers in the sacroiliac joint in humans. Reg Anesth Pain Med. 2008;33(1):36-43. doi:10.1016/j.rapm.2007.07.011.

3. Eno J-J, Boone C, Bellino M, Bishop J. The Prevalence of Sacroiliac Joint Degeneration in Asymptomatic Adults. J Bone Joint Surg Am. 2015;97(11):932-936. doi:10.2106/JBJS.N.01101. 4. Ha K-Y, Lee J-S, Kim K-W. Degeneration of sacroiliac joint after instrumented lumbar or lumbosacral fusion: a prospective cohort study over fiveyear follow-up. Spine. 2008;33(11):1192-1198. doi:10.1097/BRS.0b013e318170fd35.

5. Szadek KM, van der Wurff P, van Tulder MW,

Downloaded from http://ijssurgery.com/ by guest on April 26, 2023 
Zuurmond WW, Perez RSGM. Diagnostic validity of criteria for sacroiliac joint pain: a systematic review. J Pain. 2009;10(4):354-368. doi:10.1016/ j.jpain.2008.09.014.

6. Fortin J, Dwyer A, West S, Pier J. Sacroiliac joint: pain referral maps upon applying a new injection/ arthrography technique. Part I: Asymptomatic volunteers. Spine. 1994;19(13):1475-1482.

7. Dreyfuss P, Henning T, Malladi N, Goldstein B, Bogduk N. The Ability of Multi-Site, Multi-Depth Sacral Lateral Branch Blocks to Anesthetize the Sacroiliac Joint Complex. Pain Med.

2009;10(4):679-688. doi:10.1111/

j.1526-4637.2009.00631.x.

8. Ledonio CGT, Polly DW, Swiontkowski MF. Minimally invasive versus open sacroiliac joint fusion: are they similarly safe and effective? Clin $\mathrm{Or}$ thop. 2014;472(6):1831-1838. doi:10.1007/ s11999-014-3499-8.

9. Al-Khayer A, Hegarty J, Hahn D, Grevitt MP. Percutaneous sacroiliac joint arthrodesis: a novel technique. J Spinal Disord Tech. 2008;21(5):359-363. doi:10.1097/BSD.0b013e318145ab96.

10. Cummings J Jr, Capobianco RA. Minimally invasive sacroiliac joint fusion: one-year outcomes in 18 patients. Ann Surg Innov Res. 2013;7(1):12. doi:10.1186/1750-1164-7-12.

11. Gaetani P, Miotti D, Risso A, et al. Percutaneous arthrodesis of sacro-iliac joint: a pilot study. $J$ Neurosurg Sci. 2013;57(4):297-301.

12. Schroeder JE, Cunningham ME, Ross T, Boachie-Adjei O. Early Results of Sacro-Iliac Joint Fixation Following Long Fusion to the Sacrum in Adult Spine Deformity. Hosp Spec Surg J. 2013;10(1):30-35. doi:10.1007/s11420-013-9374-4 . 13. Vanaclocha VV, Verdú-López F, Sánchez-Pardo, $\mathrm{M}$, et al. Minimally Invasive Sacroiliac Joint Arthrodesis: Experience in a Prospective Series with 24 Patients. J Spine. 2014;3(5). doi:10.4172/ 2165-7939.1000185.

14. Cher D, Polly D, Berven S. Sacroiliac Joint pain: burden of disease. Med Devices Evid Res. 2014;7:73-81. doi:10.2147/MDER.S55197.

15. Cher DJ, Reckling WC. Quality of life in preoperative patients with sacroiliac joint dysfunction is at least as depressed as in other lumbar spinal conditions. Med Devices Evid Res. 2015;8:395-403.
doi:10.2147/MDER.S92070.

16. Sembrano JN, Polly DW. How often is low back pain not coming from the back? Spine.

2009;34(1):E27-32. doi:10.1097/

BRS.0b013e31818b8882.

17. Bernard TN, Kirkaldy-Willis WH. Recognizing specific characteristics of nonspecific low back pain. Clin Orthop. 1987;(217):266-280.

18. Schwarzer AC, Aprill CN, Bogduk N. The sacroiliac joint in chronic low back pain. Spine. 1995;20(1):31-37.

19. Maigne JY, Aivaliklis A, Pfefer F. Results of sacroiliac joint double block and value of sacroiliac pain provocation tests in 54 patients with low back pain. Spine. 1996;21(16):1889-1892.

20. Maigne JY, Planchon CA. Sacroiliac joint pain after lumbar fusion. A study with anesthetic blocks.

Eur Spine J. 2005;14(7):654-658. doi:10.1007/ s00586-004-0692-6.

21. DePalma MJ, Ketchum JM, Saullo TR. Etiology of Chronic Low Back Pain in Patients Having Undergone Lumbar Fusion. Pain Med. 2011;12(5):732-739. doi:10.1111/j.1526-4637.2011.01098.x.

22. Liliang P-C, Lu K, Liang C-L, Tsai Y-D, Wang $\mathrm{K}-\mathrm{W}$, Chen H-J. Sacroiliac joint pain after lumbar and lumbosacral fusion: findings using dual sacroiliac joint blocks. Pain Med Malden Mass.

2011;12(4):565-570. doi:10.1111/

j.1526-4637.2011.01087.x.

23. Luukkainen R, Nissilä M, Asikainen E, et al. Periarticular corticosteroid treatment of the sacroiliac joint in patients with seronegative spondylarthropathy. Clin Exp Rheumatol. 1999;17(1):88-90.

24. Luukkainen RK, Wennerstrand PV, Kautiainen $\mathrm{HH}$, Sanila MT, Asikainen EL. Efficacy of periarticular corticosteroid treatment of the sacroiliac joint in non-spondylarthropathic patients with chronic low back pain in the region of the sacroiliac joint. Clin Exp Rheumatol. 2002;20(1):52-54.

25. Cohen SP, Hurley RW, Buckenmaier CC, Kurihara C, Morlando B, Dragovich A. Randomized placebo-controlled study evaluating lateral branch radiofrequency denervation for sacroiliac joint pain. Anesthesiology. 2008;109(2):279-288. doi:10.1097/ ALN.0b013e31817f4c7c.

26. Patel N, Gross A, Brown L, Gekht G. A randomized, placebo-controlled study to assess the effi- 
cacy of lateral branch neurotomy for chronic sacroiliac joint pain. Pain Med Malden Mass.

2012;13(3):383-398. doi:10.1111/

j.1526-4637.2012.01328.x.

27. Painter CF. Excision of the os innominatum.

Arthrodesis of the sacro-iliac synchrondrosis. Boston Med Surg J. 1908;159(7):205-208.

28. Mason LW, Chopra I, Mohanty K. The percutaneous stabilisation of the sacroiliac joint with hollow modular anchorage screws: a prospective outcome study. Eur Spine J. 2013;22(10):2325-2331. doi:10.1007/s00586-013-2825-2.

29. Rudolf L, Capobianco R. Five-Year Clinical and Radiographic Outcomes After Minimally Invasive Sacroiliac Joint Fusion Using Triangular Implants. Open Orthop J. 2014;8:375-383. doi:10.2174/ 1874325001408010375.

30. Sachs D, Capobianco R, Cher D, et al. One-year outcomes after minimally invasive sacroiliac joint fusion with a series of triangular implants: a multicenter, patient-level analysis. Med Devices Evid Res. 2014;7:299-304. doi:10.2147/MDER.S56491. 31. Ledonio C, Polly D, Swiontkowski MF, Cummings J. Comparative effectiveness of open versus minimally invasive sacroiliac joint fusion. Med Devices Evid Res. 2014;2014(7):187-193. doi:10.2147/ MDER.S60370.

32. Rudolf L. Sacroiliac Joint Arthrodesis-MIS Technique with Titanium Implants: Report of the First 50 Patients and Outcomes. Open Orthop J. 2012;6:495-502. doi:10.2174/1874325001206010495. 33. Whang PG, Cher D, Polly D, et al. Sacroiliac Joint Fusion Using Triangular Titanium Implants vs. Non-Surgical Management: Six-Month Outcomes from a Prospective Randomized Controlled Trial. Int J Spine Surg. 2015;9:Article 6. doi:10.14444/2006. 34. Polly DW, Cher DJ, Wine KD, et al. Randomized Controlled Trial of Minimally Invasive Sacroiliac Joint Fusion Using Triangular Titanium Implants vs Nonsurgical Management for Sacroiliac Joint Dysfunction: 12-Month Outcomes. Neurosurgery.

2015;77(5):674-90-691. doi:10.1227/

NEU.0000000000000988.

35. Fortin JD, Falco FJ. The Fortin finger test: an indicator of sacroiliac pain. Am J Orthop Belle Mead NJ. 1997;26(7):477-480.

36. Fairbank JC, Pynsent PB. The Oswestry Dis- ability Index. Spine. 2000;25(22):2940-2952; discussion 2952.

37. EuroQol Group. EuroQol--a new facility for the measurement of health-related quality of life. Health Policy Amst Neth. 1990;16(3):199-208.

38. Ware JE Jr, Sherbourne CD. The MOS 36-item short-form health survey (SF-36). I. Conceptual framework and item selection. Med Care. 1992;30(6):473-483.

39. Hesch J, Aisenbrey J, Guarino J. Manual therapy evaluation of the pelvic joints using palpatory and articular spring tests. In: American Physical Therapy Association. Anaheim, CA; 1990.

40. Copay AG, Glassman SD, Subach BR, Berven S, Schuler TC, Carreon LY. Minimum clinically important difference in lumbar spine surgery patients: a choice of methods using the Oswestry Disability Index, Medical Outcomes Study questionnaire Short Form 36, and pain scales. Spine J.

2008;8(6):968-974. doi:10.1016/

j.spinee.2007.11.006.

41. Childs JD, Piva SR, Fritz JM. Responsiveness of the numeric pain rating scale in patients with low back pain. Spine. 2005;30(11):1331-1334.

42. Copay AG, Cher DJ. Is the Oswestry Disability Index a valid measure of response to sacroiliac joint treatment? Qual Life Res. 2016 Feb;25(2):283-292. doi:10.1007/s11136-015-1095-3.

43. Glassman SD, Copay AG, Berven SH, Polly DW, Subach BR, Carreon LY. Defining Substantial Clinical Benefit Following Lumbar Spine Arthrodesis. J Bone Jt Surg. 2008;90(9):1839-1847. doi:10.2106/JBJS.G.01095.

44. Clopper CJ, Pearson ES. The use of confidence or fiducial limits illustrated in the case of the binomial, 26 (1934) 404-416. Biometrika. 1934;26:404-416. 45. R Core Team (2013). R: A Language and Environment for Statistical Computing. Vienna, Austria http://www.R-project.org/.

46. The YODA Project. http://yoda.yale.edu/. Accessed May 27, 2016.

47. Sturesson B, Kools D, Pflugmacher R, Gasbarrini A, Prestamburgo D, Dengler J. Six-month outcomes from a randomized controlled trial of minimally invasive SI joint fusion with triangular titanium implants vs conservative management. Eur Spine J. May 2016. doi:10.1007/s00586-016-4599-9. 
48. Duhon BS, Bitan F, Lockstadt H, Kovalsky D, Cher D, Hillen T. Triangular Titanium Implants for Minimally Invasive Sacroiliac Joint Fusion: 2-Year Follow-Up from a Prospective Multicenter Trial. Int J Spine Surg. 2016;10:Article 13. doi:10.14444/3013. 49. Sachs D, Kovalsky D, Redmond A, et al. Durable intermediate- to long-term outcomes after minimally invasive transiliac sacroiliac joint fusion using triangular titanium implants. Med Devices Evid Res. 2016; doi: 10.2147/mder.s109276.

50. Burkus JK, Transfeldt EE, Kitchel SH, Watkins RG, Balderston RA. Clinical and radiographic outcomes of anterior lumbar interbody fusion using recombinant human bone morphogenetic protein-2. Spine. 2002;27(21):2396-2408. doi:10.1097/ 01.BRS.0000030193.26290.DD.

51. US Food and Drug Administration. Summary of Safety and Effectiveness. US Food and Drug Administration; 2002. http://www.accessdata.fda.gov/ cdrh_docs/pdf/P000058b.pdf.

52. Weinstein JN, Lurie JD, Tosteson TD, et al. Surgical versus Nonsurgical Treatment for Lumbar Degenerative Spondylolisthesis. $N$ Engl J Med. 2007;356(22):2257-2270. doi:10.1056/NEJMoa070302.

53. Weinstein JN, Tosteson TD, Lurie JD, et al. Surgical Versus Nonoperative Treatment for Lumbar Spinal Stenosis Four-Year Results of the Spine Patient Outcomes Research Trial: Spine. May 2010:1. doi:10.1097/BRS.0b013e3181e0f04d.

54. Weinstein JN, Lurie JD, Tosteson TD, et al. Surgical vs Nonoperative Treatment for Lumbar Disk Herniation: The Spine Patient Outcomes Research Trial (SPORT) Observational Cohort. JAMA. 2006;296(20):2451. doi:10.1001/jama.296.20.2451. 55. Polly D, Cher D, Whang PG, Frank C, Sembrano J, for the INSITE Study Group. Does Level of Response to SI Joint Block Predict Response to SI Joint Fusion? Int J Spine Surg. 2016;10:Article 4. doi:10.14444/3004.

56. Engh CA, Culpepper WJ, Engh CA. Long-term results of use of the anatomic medullary locking prosthesis in total hip arthroplasty. J Bone Joint Surg Am. 1997;79(2):177-184.

57. Hallan G, Lie SA, Furnes O, Engesaeter LB, Vollset SE, Havelin LI. Medium- and long-term performance of 11,516 uncemented primary femoral stems from the Norwegian arthroplasty register. $J$ Bone Joint Surg Br. 2007;89(12):1574-1580. doi:10.1302/0301-620X.89B12.18969. 58. Meding JB, Galley MR, Ritter MA. High survival of uncemented proximally porous-coated titanium alloy femoral stems in osteoporotic bone. Clin Orthop. 2010;468(2):441-447. doi:10.1007/ s11999-009-1035-z.

59. Ackerman SJ, Polly DW Jr, Knight T, Holt T, Cummings J Jr. Nonoperative care to manage sacroiliac joint disruption and degenerative sacroiliitis: high costs and medical resource utilization in the United States Medicare population. J Neurosurg Spine. 2014;20(4):354-363. doi:10.3171/

2014.1.SPINE13188.

60. Ackerman S, Polly DW, Holt T, Cummings JT, Knight T. Management of sacroiliac joint disruption and degenerative sacroiliitis with nonoperative care is medical resource-intensive and costly in a United States commercial payer population. Clin Outcomes Res. 2014;2014(6):63-74. doi:10.2147/CEOR.S54158. 61. Cher DJ, Frasco MA, Arnold RJ, Polly DW. Cost-effectiveness of minimally invasive sacroiliac joint fusion. Clin Outcomes Res CEOR. 2016;8:1-14. doi:10.2147/CEOR.S94266.

62. Polly $\mathrm{D}$, Cher D. Ignoring the sacroiliac joint in chronic low back pain is costly. Clin Outcomes Res. 2016;Volume 8:23-31. doi:10.2147/CEOR.S97345. 63. Saavoss J, Koenig L, Cher DJ. Productivity Benefits of Minimally Invasive Surgery in Patient with Chronic Sacroiliac Joint Dysfunction. Clin Outcomes Res. 2016;2016(8):77-85. doi:10.2147/CE-

OR.S101607.

64. Khurana A, Guha AR, Mohanty K, Ahuja S. Percutaneous fusion of the sacroiliac joint with hollow modular anchorage screws: clinical and radiological outcome. J Bone Joint Surg Br.

2009;91(5):627-631. doi:10.1302/

0301-620X.91B5.21519.

65. Endres $S$, Ludwig E. Outcome of distraction interference arthrodesis of the sacroiliac joint for sacroiliac arthritis. Indian J Orthop. 2013;47(5):437-442. doi:10.4103/0019-5413.118197. 66. Wise CL, Dall BE. Minimally invasive sacroiliac arthrodesis: outcomes of a new technique. J Spinal Disord Tech. 2008;21(8):579-584. doi:10.1097/ BSD.0b013e31815ecc4b. 
67. Beck CE, Jacobson S, Thomasson E. A Retrospective Outcomes Study of 20 Sacroiliac Joint Fusion Patients. Cureus. 2015;7(4):e260. doi:10.7759/ cureus.260.

68. Delitto A, Piva SR, Moore CG, et al. Surgery versus nonsurgical treatment of lumbar spinal stenosis: a randomized trial. Ann Intern Med. 2015;162(7):465-473. doi:10.7326/M14-1420.

\section{Disclosures \& COI}

All authors conduct clinical research for SI-BONE. The study was sponsored by SI-BONE (San Jose, CA). David Polly has no financial interest in SIBONE. Peter Whang is a paid SI-BONE consultant participating primarily in educational events. Clay Frank is an SI-BONE consultant participating primarily in educational events, but receives only rea- sonable expense reimbursement as compensation. Daniel Cher and Kathryn Wine are SI-BONE employees.

\section{Corresponding Author}

David Polly, Departments of Orthopedic Surgery and Neurosurgery, University of Minnesota, 2512 South 7th Street, Suite R200, Minneapolis, MN 55454, pollydw@umn.edu.

Published 23 August 2016.

This manuscript is generously published free of charge by ISASS, the International Society for the Advancement of Spine Surgery. Copyright @ 2016 ISASS. To see more or order reprints or permissions, see http://ijssurgery.com. 